\title{
PIMENTA NOS OLHOS DOS OUTROS É... CHILLI BEANS! A PERSONALIDADE DA MARCA AOS “OLHOS” DOS CONSUMIDORES ${ }^{1}$
}

\author{
André Luiz Maranhão de Souza Leão \\ aleao21@hotmail.com \\ Universidade Federal de Pernambuco - Recife, PE / Brasil \\ Thiago Ianatoni Camargo \\ ianatoni@gmail.com \\ Universidade Federal de Pernambuco - Recife, PE / Brasil \\ Rodrigo César Tavares Cavalcanti \\ Universidade Federal de Pernambuco - Recife, PE / Brasil \\ rodrigoctc@gmail.com
}

http://dx.doi.org/10.1590/1413-2311.0252013.42911

Recebido em 03/04/2014

Aprovado em 01/09/2014

Disponibilizado em 01/12/2014

Avaliado pelo sistema double blind review

Revista Eletrônica de Administração

Editor: Luís Felipe Nascimento

ISSN 1413-2311 (versão on-line)

Editada pela Escola de Administração da Universidade Federal do Rio Grande do Sul.

Periodicidade: Quadrimestral

Sistema requerido: Adobe Acrobat Reader.

\section{RESUMO}

Cada vez mais as organizações buscam estabelecer vínculos entre suas marcas e os consumidores como estratégia para construção de valor de modo a estabelecer trocas. Na academia, esta questão aparece em estudos que se localizam na interseção entre as áreas de branding e de marketing de relacionamento. Neste intuito, a personalidade de marca, referente à atribuição de características humanas à mesma, se apresenta como uma noção primordial no fomento a esse elo. O presente estudo investiga a percepção dos consumidores da Chilli Beans, maior vendedora de óculos escuros da América Latina, sobre a marca. Desta forma, o objetivo desta pesquisa foi identificar e avaliar as características humanas que compõem a personalidade da marca Chilli Beans sob a ótica de seus consumidores. A investigação se caracteriza como um estudo qualitativo exploratório, realizado por meio de entrevistas em profundidade e analisadas mediante a análise de discurso funcional. Nossos achados indicam treze categorias que, em suas relações, nos levaram à identificação de três perfis que compõem as características ônticas da marca. Implicações teóricas e práticas, bem como indicações de futuras pesquisas são consideradas.

Palavras-Chave: Personalidade de marca; Pesquisa qualitativa; Análise de discurso; Chilli Beans; Branding.

\footnotetext{
${ }^{1}$ O presente estudo foi realizado com o apoio do Conselho Nacional de Desenvolvimento Científico e Tecnológico (CNPq), que fomentou, por meio de custeio e bolsa, a pesquisa que deu origem a este artigo.
}

REAd | Porto Alegre - Edição 79 - Nº 3 - setembro/dezembro 2014 - p. 773-792 
Pimenta nos olhos dos outros é... Chilli Beans! A personalidade da marca aos “olhos” dos consumidores

\title{
PEPPER IN OTHER'S EYES IS... CHILLI BEANS! BRAND PERSONALITY AT CONSUMERS “EYES”
}

\begin{abstract}
More and more organizations seek to establish links between their brands and consumers as value construction strategy in pursuit to establish exchanges. Within the academy, this point appears in studies located at the intersection between branding and relationship marketing. To this end, brand personality, referred to the assignment of human characteristics to it, serves as a primary notion in foresting this link. Present study investigates the perception of Chilli Beans' consumers, the Latin America's sunglasses largest seller, about the brand. Thou, the objective of this research was to identify and evaluate human characteristics that make up Chilli Beans' personality based on its consumers' perspective. The research is characterized as an exploratory qualitative study, conducted through in depth interviews and analyzed using functional discourse analysis. Our findings indicate thirteen categories that, in their relations, propitiated us to identify three profiles that make up the brand ontic characteristics. Theoretical and practical implications, as well as directions for future research, are considered.
\end{abstract}

Keywords: brand personality; Qualitative research; Discourse analysis; Chilli Beans; Branding.

\section{PIMIENTA EN LOS OJOS DE LOS DEMÁS ES... CHILLI BEANS! LA PERSONALIDAD DE LA MARCA A LOS "OJOS" DE LOS CONSUMIDORES}

\section{RESUMEN}

Cada vez más las organizaciones buscan establecer vínculos entre sus marcas y los consumidores como una estrategia para crear valor con el fin de establecer intercambios. En el ámbito académico, este problema aparece en los estudios que se encuentran en la intersección entre las áreas de branding y marketing relacional. Para este fin, la personalidad de la marca, que se refiere a la atribución de características humanas a esta, se presenta como un concepto primordial en el fomento de este enlace. Este estudio investiga la percepción del consumidor de Chilli Beans, el mayor vendedor de gafas de sol de América Latina, sobre la marca. Por lo tanto, el objetivo de esta investigación fue identificar y evaluar las características humanas que componen la personalidad de la marca Chilli Beans desde la perspectiva de sus clientes. La investigación se caracteriza como un estudio cualitativo exploratorio realizado a través de entrevistas en profundidad y analizados mediante análisis de discurso funcional. Nuestros hallazgos indican trece categorías que, en sus relaciones, nos ha llevado a identificar tres perfiles que componen las características de la marca. Se consideran las implicaciones teóricas y prácticas, así como direcciones para investigaciones futuras.

Palabras clave: personalidad de la marca; la investigación cualitativa; análisis de discurso; Chilli Beans; Branding.

\section{INTRODUÇÃO}

As marcas têm se apresentado com destaque enquanto critério de decisão na dinâmica de escolha dos consumidores nas últimas décadas. Com isto, passaram a ganhar crescente

REAd | Porto Alegre - Edição 79 - N 3 - setembro/dezembro 2014 - p. 773-792 
André Luiz Maranhão de Souza Leão, Thiago Ianatoni Camargo \& Rodrigo César Tavares Cavalcanti

atenção das organizações, em suas estratégias de gerenciamento, a fim de otimizar a sua imagem nos mercados em que atuam (KELLER, 2011; SONNIER; AINSLE, 2011). Por outro lado, as empresas também se esforçam para estabelecer relacionamentos duradouros com os clientes (PALMATIER et al., 2011; PATSIOURA et al., 2011; ANTUNES; RITA, 2008). Entre estes dois temas, situam-se os estudos sobre relacionamentos marca-consumidor (FOURNIER, 1998; BRITO, 2010; SUNG; CHOI, 2010; SWAMINATHAN; et al., 2007). Essa relação se torna mais evidente por meio da compreensão sobre o conceito de personalidade de marca, em que se assume que os consumidores interagem com as marcas como se fossem pessoas, possuidoras de características humanas (AAKER, 1997; GROHMANN, 2009; MÄLAR; et al., 2011).

Com o desenvolvimento crescente da economia nacional, parece-nos coerente que marcas nacionais se tornem cada vez mais relevantes, o que demanda da academia brasileira um esforço em estudos que possam propiciar conhecimento acerca de nossas marcas, uma vez que vários estudos realizados no Brasil têm contribuído para a consolidação acerca do conhecimento de marcas internacionais, sobretudo às de condição global. Especificamente sobre a noção de personalidade de marca, esse não demonstra um tema explorado em toda a sua potencialidade no país. Quando encontrados trabalhos sobre essa temática, o que evidenciamos são um maior direcionamento às tentativas de adaptação de certas escalas de mensuração, visando corroborar com teorias estabelecidas, bem como adaptações dos contextos internacionais, à realidade brasileira.

A Chilli Beans é uma marca destacada no cenário nacional por seu rápido crescimento e sucesso. A marca surgiu em 1997, importando óculos de sol oriundos dos Estados Unidos. Inicialmente foram comercializados em estabelecimentos de moda de São Paulo e em seguida em feiras de moda itinerante e uma loja própria em uma galeria no centro daquela cidade. No ano 2000 iniciaram-se suas operações por meio de pequenos quiosques em malls de shopping centers e, já no ano seguinte inicia sua base de franquias. A partir desta mudança, passou a criar seus próprios produtos, terceirizando a produção. Apenas em 2002 abriria sua primeira loja, sem abandonar o formato de quiosques. Em 2005 abriu sua primeira loja internacional, em Lisboa. Atualmente, a marca está presente em mais de 600 pontos de venda por todo o país. Internacionalmente, além de Portugal, expandiu suas atividades para Estados Unidos, Colômbia, Peru, Kuwait e Israel. Encontra-se na posição de maior vendedora de óculos da América Latina (CHILLI BEANS, 2014).

Tendo em vista a relevância de se conhecer as marcas a partir da ótica de seus consumidores e assumindo a noção de personalidade de marca como norteadora da REAd | Porto Alegre - Edição 79 - N 3 - setembro/dezembro 2014 - p. 773-792 
Pimenta nos olhos dos outros é... Chilli Beans! A personalidade da marca aos “olhos” dos consumidores

compreensão do relacionamento entre as marcas e seus clientes, a presente pesquisa tem por objetivo identificar e avaliar as características humanas que compõem a personalidade da marca Chilli Beans sob a ótica de seus consumidores. Para tal, no entanto, ao invés de adotar o conceito de personalidade de marca como um construto teórico e analisar suas variáveis por meio de mensuração e uso de escalas, adotamos uma postura de caráter mais indutivo, de forma a capturar a visão dos consumidores de forma mais espontânea, preservando a maneira particular como se expressam em relação à marca estudada.

Explorar o conceito de personalidade de marca no contexto das marcas brasileiras justifica-se por constituir-se como parte de um campo fecundo de pesquisas na área de branding. Desvendar a personalidade da Chilli Beans sob a perspectiva de seus consumidores se mostra como importante tanto para a academia quanto para a prática de marketing, já que pode contribuir para a compreensão de quais aspectos de uma marca brasileira de sucesso são assimilados e admirados pelos seus consumidores. Por outro lado, estudar a marca Chilli Beans não se faz relevante apenas por sua singularidade como marca exitosa, mas principalmente, por ser representativa de uma possibilidade de generalização analítica (FLICK, 2009; BAUER et al., 2002).

Ademais, o objetivo que ora propomos encontra um espaço pouco explorado do estudo das marcas, ao privilegiar uma perspectiva naturalista da visão dos consumidores e que se alinha a uma emergente agenda de pesquisa de abordagem interpretativista em marketing, que assume a realidade como uma construção sociocultural (BERGER; LUCKMANN, 2009; DENZIN; LINCOLN, 2005).

\section{PERSONALIDADE DE MARCA}

A ideia de personalidade de marca pode ser exposta como um conjunto de qualidades humanas relacionadas a uma marca. Aaker (1997) gerou uma escala, na qual o construto é divido em cinco dimensões de traços de personalidade (austeridade, sofisticação, sinceridade, excitação e competência), chamadas de big five, que, por sua vez, são especificadas por meio de quinze facetas. Os estudos sobre personalidade de marca têm se fundamentado a partir desta lógica dimensional do construto (e.g., GROHMANN, 2009; KIM et al., 2010; MADRIGAL; BOUSH, 2008).

Aaker (1996) propõe que essas qualidades humanas da marca são originadas por seus elementos, tais como produtos, categoria, atributos, embalagem, preço, imagens, símbolos, ponto de venda, estilo de comunicação, endosso de celebridades etc. Esses componentes fazem a mediação entre a marca e seus consumidores, em uma espécie de relacionamento

REAd | Porto Alegre - Edição 79 - Nº 3 - setembro/dezembro 2014 - p. 773-792 
André Luiz Maranhão de Souza Leão, Thiago Ianatoni Camargo \& Rodrigo César Tavares Cavalcanti

entre duas pessoas, fazendo alusão ao conceito de relacionamento de marca. Estes relacionamentos, por sua vez, tanto podem ser funcionais como amigáveis (AAKER, 1997). Porém, a marca não se encontra passiva nessa dinâmica. Ela assume um papel ativo ao emitir algo, assim como faria uma pessoa (BLACKSTON, 1993). Pensando assim, Fournier (1998) afirma que a marca pode ser um parceiro ativo nessa relação. Do mesmo modo que o comportamento dos indivíduos afeta a percepção dos outros em sua personalidade, a personalidade de uma marca é influenciada por seus comportamentos, definindo também o tipo de relacionamento a ser estabelecido com seus consumidores.

Assim, a atitude da marca é relevante e a sua personalidade não é apenas uma percepção do consumidor, passiva de manipulação. As marcas possuem múltiplas personalidades, como acontece com as pessoas quando em contato com diferentes contextos e papéis. Seguindo este raciocínio, uma personalidade de marca efetiva é aquela que se alinha ao seu contexto de uso e a auto expressão dos consumidores. Corroborando com esta perspectiva, McCracken (1984; 1986) apresenta a personalidade da marca como integrante do significado cultural na constituição de selfs sociais das pessoas. Dessa forma as marcas veiculam a expressão das identidades de seus consumidores, uma vez que esses indivíduos usam bens e posses não só de maneira funcional, mas também de forma simbólica, constituindo significados em suas vidas (MÄLAR et al., 2011).

Desta forma, a personalidade de marca pode interferir na escolha dos produtos feita pelos consumidores, já que esta característica se destaca no processo de socialização (SWAMINATHAN et al., 2009). As marcas podem fornecer aos seus consumidores a noção de posse de uma identidade singular ou a noção de existir uma identidade coletiva que o une a outros escolhidos, assim como aponta um desejo de ser aceito (ESCALAS; BETTMAN, 2003). No entanto, devemos evidenciar que o envolvimento do consumidor com a personalidade da marca ocorre de tal maneira que este a assimila de acordo com suas próprias crenças e personalidades (PARK; ROEDDER JOHN, 2010), sugerindo certa disposição entre as partes.

Em relação ao cenário brasileiro de estudos sobre personalidade de marca, em uma revisão às publicações científicas nacionais, não são muitos os trabalhos encontrados. $\mathrm{O}$ estudo de Muniz e Marchetti (2005) apresenta um esforço para adaptar a escala de Aaker (1997) de mensuração da personalidade de marca para um contexto brasileiro. Eles utilizaram as mesmas marcas globais da pesquisa original e chegaram a conclusões diferentes às de outros trabalhos realizados com as mesmas marcas em localidades outras. Esta mesma escala adaptada foi utilizada para entender a personalidade de uma marca de calçados brasileira

REAd | Porto Alegre - Edição 79 - N 3 - setembro/dezembro 2014 - p. 773-792 
Pimenta nos olhos dos outros é... Chilli Beans! A personalidade da marca aos “olhos” dos consumidores

(BICHUETI; et al., 2010), bem como a personalidade de marcas-cidades (PETROSKI; et al., 2010).

Añaña e Nique (2009) estudaram a interferência de subculturas regionais brasileiras na construção e percepção da imagem da marca Nike por consumidores brasileiros. Para tanto, utilizaram uma intersecção entre a escala de personalidade de Aaker (1997) e a escala de valores Rokeach (1968; 1973). Os resultados reafirmam a influência da cultura na constituição da imagem da marca. Leão e outros (2007), por sua vez, analisaram os valores humanos emanados pelas marcas a partir da ótica dos consumidores. $\mathrm{O}$ trabalho defende que certos valores não são respectivos apenas de uma marca, mas sim, significações da categoria principal em que essa se insere. Mengarelli (2008) averiguou como adolescentes demonstram suas subjetividades por meio do simbolismo encontrado em produtos e marcas. Em suas considerações, concluiu que tais formas de expressão se revelam efêmeras entre este perfil de consumidores.

A noção de personalidade da marca é evidenciada também na integração a outros temas pesquisados, como em estudos sobre estratégias de reposicionamento da marca (SERRALVO; FURRIER, 2008; DALFOVO; PEDROSO, 2008); para entender a influência de determinadas estratégias comunicativas na construção de personalidades de certas marcas (FISHER, 2009; PONTES; PARENTES, 2008); sobre a relevância da brasilidade como atributo na construção de marcas brasileiras luxuosas no mercado global (FINESTRALI; GARRIDO, 2010); por constituir-se parte do processo estratégico de branding em segmentos diversos (LEITE; et al., 2012; OLIVEIRA; et al., 2010; CRESCITELLI; GIRALDI, 2009).

\section{PROCEDIMENTOS METODOLÓGICOS}

A presente pesquisa se apresenta como qualitativa básica (MERRIAM, 1998), de caráter exploratório, alinhada ao paradigma interpretativista de pesquisa, no qual o pesquisador é ativo na construção do saber e a realidade é vista como influenciada pela sociedade, cultura e história (PAIVA JR; et al, 2008; DENZIN; LINCOLN, 2005). Em virtude desta escolha, o texto é escrito em primeira pessoa, conduta alinhada à dimensão axiológica deste paradigma, conforme Denzin e Lincoln (2005). Neste sentido, a opção pela primeira pessoa do plural deve-se não somente ao fato do artigo ter sido realizado por mais de um pesquisador, mas, sobretudo, por, nesta abordagem, entender-se que tanto os participantes da pesquisa como fontes de informação (i.e., entrevistados) quanto os autores das obras consultadas sejam coparticipantes da construção do conhecimento produzido. Trata-se ainda de um estudo de caráter semi-indutivo, em que a teoria é adotada como uma referência de aporte inicial,

REAd | Porto Alegre - Edição 79 - N 3 - setembro/dezembro 2014 - p. 773-792 
André Luiz Maranhão de Souza Leão, Thiago Ianatoni Camargo \& Rodrigo César Tavares Cavalcanti

norteando o caminho da pesquisa, e servindo como lente para interpretação aos dados coletados, permitindo a identificação de categorias empíricas (LEÃO; et al., 2009).

O método de coleta de dados foi a entrevista em profundidade não estruturada, com base em um tópico-guia (FLICK, 2009) elaborado com quatro questões abertas, sendo uma do tipo filtro, para avaliar a capacidade de resposta do entrevistado sobre o assunto (marca) específico, e as demais voltadas ao significado da marca para o consumidor, sua relevância e o relacionamento entre as partes. Os entrevistados foram selecionados aleatoriamente, por meio da indicação de outros participantes, conforme orientação da técnica "bola de neve" (BERNARD, 1994), de forma que todos os entrevistados conhecessem a marca pesquisada. A quantidade de pesquisas foi determinada por critério de saturação (THIRY-CHERQUES, 2009; BAUER; AARTS, 2002), o que nos levou a um total de 16 entrevistas, sendo que na décima quarta houve saturação dos dados.

Para análise dos dados recorremos ao método de análise funcional de discurso, que assume a fala como discurso social (STILLER, 1998) em que a compreensão do que é dito se baseia no contexto (WITTGENSTEIN, 2005), o que se configura como uma abordagem pragmática de análise (MATTOS, 2005). Como estrutura de procedimento analítico, adotamos a estratégia sugerida por Gill (2002) como referência, que indica os seguintes passos: leitura cética das transcrições, de modo a desconstruir o texto em unidades que expressem sentido coerente e consistente à pergunta de pesquisa; codificação dos textos, em que as unidades de análise são agrupadas em categorias distintas; análise propriamente dita, quando o pesquisador procura convergir os dados aproximados; e, por fim, o teste de dados, em que se utiliza critérios de qualidade (validade e confiabilidade) da pesquisa qualitativa (PAIVA JR; et al., 2011), conforme ficará evidente.

Sendo assim, numa primeira etapa as entrevistas foram transcritas por um profissional habilitado. Cada entrevista foi recebida por um dos pesquisadores para validação de sua transcrição em relação à entrevista gravada. Na sequência, os demais autores, alternadamente, fizeram mais duas rodadas desta validação. Tal procedimento, além de validar a transcrição das entrevistas, possibilitou aos pesquisadores a familiarização com o texto. Para tal, cada entrevista foi lida pelo menos duas vezes antes da análise.

Na etapa seguinte, os pesquisadores passaram à codificação das entrevistas, eliciando dos textos categorias relativas à personalidade da marca. Em seguida foram analisadas as relações existentes entre estas categorias, o que culminou num mapa de relações entre as mesmas. Esses procedimentos de análise foram realizados conforme o conceito de intercoding reliability (MILES; HUBERMAN, 1994), no qual as entrevistas recebem a análise de

REAd | Porto Alegre - Edição 79 - N 3 - setembro/dezembro 2014 - p. 773-792 
Pimenta nos olhos dos outros é... Chilli Beans! A personalidade da marca aos “olhos” dos consumidores

dos dois pesquisadores que, posteriormente, triangulam seus achados individuais entre si. Por fim, tal análise ainda foi validada por um terceiro pesquisador, responsável pela coordenação da pesquisa.

A análise dos dados foi realizada com o suporte de um programa do tipo CAQDAS (Computer-Aided Qualitative Data Analysis Software), que serve como apoio à organização e escrutínio dos dados (KELLE, 2002). O software permite a armazenagem das entrevistas, favorecendo-nos na organização e cruzamento destas. Todo o processo de codificação e determinação de relações, bem como a elaboração do mapa que apresenta tais relações, foi realizado no ambiente do programa.

Passamos a apesentar os resultados desse procedimento analítico. Tendo em vista atender a mais um importante critério de qualidade da pesquisa qualitativa, optamos por fazêlo da forma mais rica e detalhada possível, no intuito de tornar o estudo inteligível e com maior clareza nos procedimentos, possibilitando sua transferência (PAIVA JR; et al., 2011).

\section{DESCRIÇÃO DOS RESULTADOS}

As características da personalidade de marca da Chilli Beans foram identificadas em 13 categorias. Essas categorias foram nomeadas com adjetivos, uma vez que se referem a qualidades humanas, adequando-se, portanto, ao conceito de personalidade de marca. 


\section{André Luiz Maranhão de Souza Leão, Thiago Ianatoni Camargo \& Rodrigo César Tavares} Cavalcanti

Quadro 1 - Descrição das categorias

\begin{tabular}{|c|c|}
\hline Acessível & Refere-se à facilidade de acesso à marca. Remete ao reconhecimento de preços justos. \\
\hline Alegre & $\begin{array}{l}\text { Refere-se à aura de descontração da marca. Remete ao uso dos produtos da marca em ambientes de } \\
\text { diversão e de presença intensiva, tais como festas e shows. }\end{array}$ \\
\hline Atenciosa & $\begin{array}{l}\text { Refere-se ao cuidado dispensado pela marca. Remete ao atendimento prestado pelos funcionários (e.g., } \\
\text { a demonstração de conhecimento, sugerindo e opinando sobre a escolha dos produtos; bom trato; } \\
\text { afetuosidade; e atitude de facilitador as trocas de produtos) estabelecendo aproximação e intimidade. }\end{array}$ \\
\hline Autêntica & $\begin{array}{l}\text { Refere-se à genuinidade da marca. Expressa-se pela singularidade impetuosa do design dos produtos, } \\
\text { da comunicação da marca, da atmosfera das lojas e do estilo do atendimento. }\end{array}$ \\
\hline Comum & $\begin{array}{l}\text { Refere-se à indistinção da marca. Remete à falta de presença na mídia e à sua popularização, mediante } \\
\text { a adoção desta por pessoas de diferentes idades, grupos e classes sociais, sendo, por isso, assumida } \\
\text { como uma opção secundária e, por vezes, mencionada em tom de estigma. }\end{array}$ \\
\hline Distinta & $\begin{array}{l}\text { Refere-se à diferenciação da marca. Remete à qualidade e ao estilo de seus produtos, bem como à } \\
\text { seletividade em relação aos seus clientes. }\end{array}$ \\
\hline Diversificada & Refere-se à variedade de opções da marca. Especificamente em relação à sua oferta de produtos. \\
\hline Divertida & $\begin{array}{l}\text { Refere-se à aura hedônica da marca. Está relacionada ao clima de festa (sobretudo do tipo "raves") } \\
\text { percebido nas cores, materiais e modelos dos produtos. }\end{array}$ \\
\hline Estilosa & $\begin{array}{l}\text { Refere-se à dimensão estética da marca. Foi identificada por meio do design e das cores dos produtos, } \\
\text { bem como da simplicidade, conforto e música ambiente das lojas. }\end{array}$ \\
\hline Jovial & $\begin{array}{l}\text { Refere-se à aura juvenil da marca. Remete ao fato dos produtos e da comunicação da marca serem } \\
\text { dirigidos aos e condizentes com os jovens. }\end{array}$ \\
\hline Mercantil & $\begin{array}{l}\text { Refere-se à percepção de finalidade puramente comercial da marca. Sugere que os esforços de } \\
\text { comunicação e criação de modelos de produtos da marca são dirigidos apenas à sua mercantilização. }\end{array}$ \\
\hline Midiática & Refere-se à difusão da marca. Remete à sua presença nos meios de comunicação de massa. \\
\hline Sensual & $\begin{array}{l}\text { Refere-se à erotização da marca. Está presente na própria logomarca (nome e símbolos) e em suas } \\
\text { peças de comunicação. }\end{array}$ \\
\hline
\end{tabular}

Fonte: Elaboração dos autores.

O Quadro 1 apresenta tais categorias e suas respectivas descrições. Por serem todas de caráter empírico, as descrições expõem uma primeira parte explanatória, de caráter conceitual, seguido de um detalhamento de como foram identificadas nos dados, relacionando-as continuamente a elementos (i.e., características) da marca.

Após a identificação das categorias, analisamos as relações existentes entre as mesmas. Debruçando-nos sobre as transcrições das entrevistas, mapeamos situações em que as falas dos entrevistados revelaram diferentes categorias conectadas. Ao fim de tal processo, foi possível construir um mapa de relações entre as categorias (Fig. 1). A seguir, passamos a ilustrar cada uma destas relações, o que será feito a partir das categorias com mais relações constituídas.

REAd | Porto Alegre - Edição 79 - N 3 - setembro/dezembro 2014 - p. 773-792 
Pimenta nos olhos dos outros é... Chilli Beans! A personalidade da marca aos “olhos” dos consumidores

\section{Comunicativa}

Exibicionista

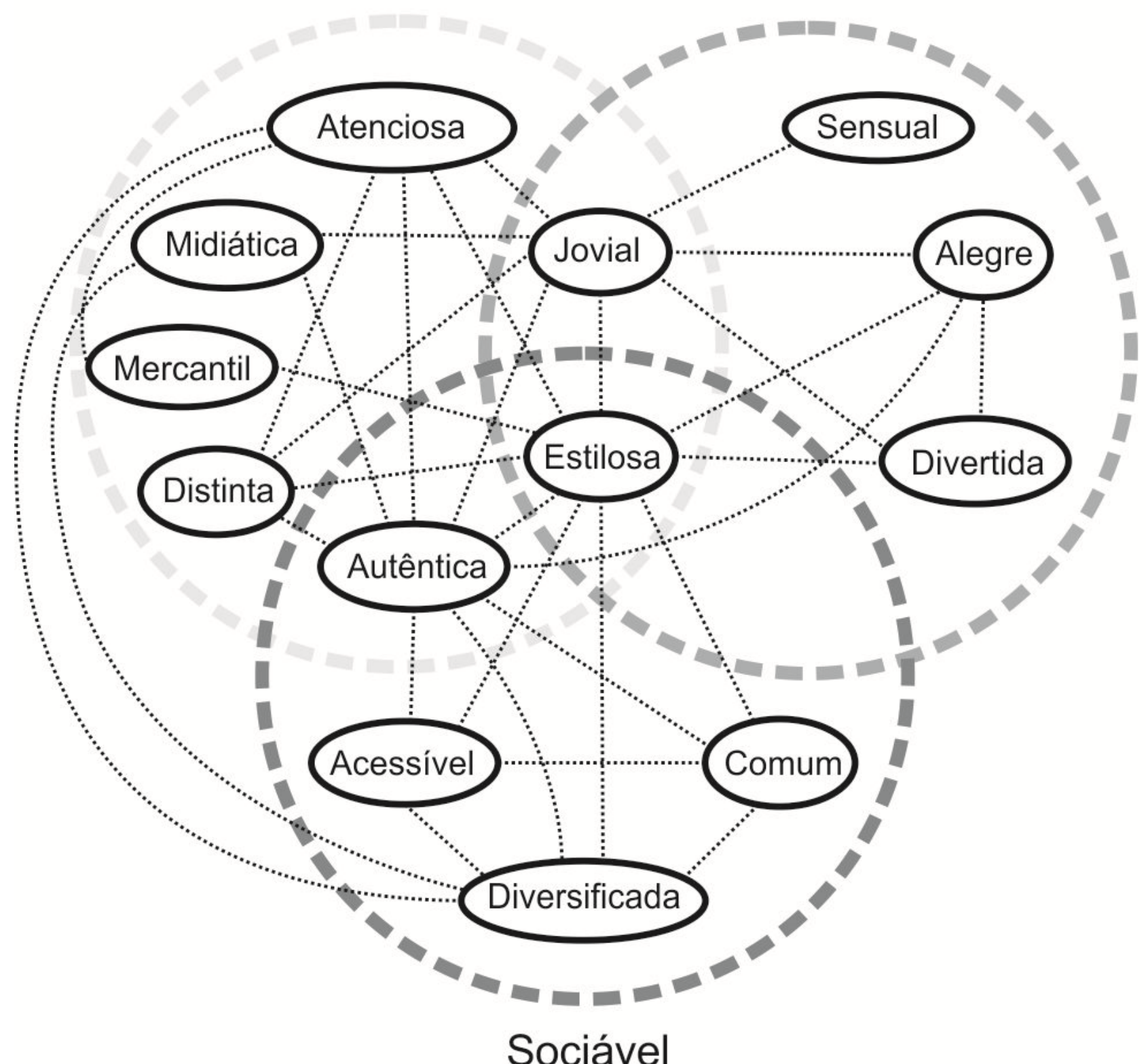

Figura 1 - Relações entre as categorias Fonte: Elaboração dos autores.

Das treze categorias da pesquisa, Estilosa se relaciona com dez. A relação entre Estilosa e Autêntica indica que a estética da marca se revela de forma singular. Esta relação pode ser exemplificada na seguinte passagem: “... os vendedores (são) super jovens, [...] é um cabelo ou um estilo, nunca é uma pessoa normal. [...] Os próprios óculos (que) eles escolhem são justamente pra chamar a atenção. E pelo estilo da loja, mesmo, jogo de luz, de cores”.

A relação entre Estilosa e Distinta indica que a dimensão estética da marca emana diferenciação à mesma, bem como a quem a utiliza, como é evidenciado na fala de um entrevistado que discorre sobre sua relação com a marca: “Eu uso um relógio diferente, [...] 
André Luiz Maranhão de Souza Leão, Thiago Ianatoni Camargo \& Rodrigo César Tavares Cavalcanti

um óculos que tem uma cor que normalmente não encontra por aí. Fora isso, a marca Chilli Beans, [...] ela tenta procurar modelos novos, atuais. Tanto é que a cada semana são produzidos modelos de óculos diferentes”. Esse mesmo depoimento evidencia como a categoria Estilosa se relaciona com Diversificada, uma vez que demonstra como a diversificação de modelos da marca se apresenta como uma marca do seu estilo.

Outro trecho de entrevista ajuda-nos a ilustrar outras duas relações de Estilosa: “Até a própria loja é composta de jovem. Por isso que eu, até falei, que ela é uma marca pra jovens, a loja tem que ter pessoas jovens, descoladas, que tão ali pra facilitar, pra mostrar o que é bom, não tem muito empecilho pra nada”. Uma das relações é a estabelecida com Jovial, o que nos permite entender sobre como o design dos elementos da marca remete a um espírito jovem. A segunda relação acontece com Atenciosa, articulando o modo como os funcionários da loja atendem em consonância com o estilo da marca.

Ao se relacionar com Divertida e com Alegre, a categoria Estilosa suscita que a estética da marca é intrínseca à aura de descontração da marca, estabelecendo uma relação identitária a momentos de entretenimento, como no trecho que segue: "Nas últimas vezes em que eu visitei a Chilli Beans, a única coisa que ela quis me proporcionar foi o colorido, essa coisa tipo 'Restart', essas coisas tipo Techno Dance, aqueles óculos todos, pra sair na noite, essas coisas”.

A relação que Estilosa possui com Acessível, por sua vez, faz emergir a compreensão de que a marca é assimilada de forma a representar um produto bonito a um preço justo, como se pode perceber nesse trecho: “... também tem outra coisa que me agrada muito na marca, que é a relação custo-benefício. Eu acho os óculos muito agradáveis, muito gostosos de usar, estilosos, [...] com um preço muito bacana, diferente de outras marcas que eu já usei”.

Já a relação entre Comum e Estilosa revela que a marca se destina a diferentes públicos, mesmo carregando uma identidade visual particular: "Eles [...] agradam o público como um todo. Vão do kids, dos óculos infantis, aos óculos mais clássicos, como também oferecem algo como o fashion, com a moda, que aí é onde eu falo que me provoca, é o que me chama a atenção".

Finalmente, Estilosa se relaciona com Mercantil, sugerindo que a estética da marca é intencionalmente voltada para o mercado, como no trecho que segue: “... eu ligo muito a Chilli Beans a design, a uma inovação, modernidade, a uma coisa meio que pós-moderna. [...] a marca tem essa estética, [...] pra um público-alvo e, claro, (para) vender”.

Autêntica tem o maior número de relações depois de Estilosa. Ela se relaciona com nove categorias, incluindo Estilosa (já apresentada). Sua relação com Distinta evidencia que REAd | Porto Alegre - Edição 79 - N 3 - setembro/dezembro 2014 - p. 773-792 
Pimenta nos olhos dos outros é... Chilli Beans! A personalidade da marca aos “olhos” dos consumidores

a diferenciação da marca em relação às outras se dá por suas características singulares. Com Atenciosa, a relação de Autêntica se evidencia pela percepção de que o atendimento dos vendedores seja característico da marca. Estas duas relações podem ser evidenciadas por um mesmo relato: "É no sentido de ser diferente das demais, de conseguir se destacar no segmento que ela atua, por diversas questões: atendimento, produto, a forma de lidar com os clientes...”.

A partir da mesma lógica, demonstramos a relação de Autêntica com Alegre e com Comum simultaneamente: "Eu venho notando que ela tem um conceito bastante amplo em relação a querer acertar no seu público-alvo. Ela é bastante objetiva no que ela quer. A gente já vê pelo nome da marca, Chilli Beans: pimenta quente. Tem um conceito de algo pra cima, alto astral”. A relação com Alegre se revela como uma faceta de singularidade que se mostra por meio de sua aura de descontração. No caso de Comum, embora singular, a marca se mostra como representante de diferentes perfis de consumidores.

Na relação entre Autêntica e Jovial revela-se a jovialidade da marca como elemento de sua expressividade particular. Observamos isso no trecho que segue: "O estilo da Chilli Beans é ser moderno. Então, quando eu tenho uns óculos com armação diferente, [...] com formato diferente, eu penso logo na marca”.

Autêntica se relaciona ainda com Diversificada e com Midiática. No primeiro caso, a quantidade de modelos em oferta é percebida como uma singularidade da marca. No segundo, a relação se refere à forma como a marca se mostra em sua comunicação de forma característica. “Acho fantástica a forma como eles se comunicam. [...] Lembro-me de várias propagandas (dizendo) 'tenha vários'. Você se veste cada dia com uma roupa diferente, com uma cor diferente, por que todo dia os mesmos óculos?”.

Por último, Autêntica se relaciona com Acessível, fazendo crer que embora exista a sua singularidade, a marca é comercializada por um valor acessível, conforme observamos nesse trecho de entrevista: “... uma marca inovadora, [...] com peças diferenciadas e com preço, com custo-benefício muito bom”.

Jovial é a terceira categoria com maior número de relações. Ela se relaciona com as categorias Estilosa e Autêntica (relações já apresentadas) e com outras seis. Em uma interrelação com Alegre e com Divertida, destaca-se a ligação entre o espírito juvenil e o temperamento festeiro, assim como remete a entretenimentos que enaltecem a diversão, como se demonstra na seguinte passagem: "É bem alegre, eu diria. Alegre no bom sentido, [...] de uma jovialidade gritante. Se pegar a party people como uma geração ou como um grupo, acho que a Chilli Beans está bem dentro disso”.

REAd | Porto Alegre - Edição 79 - N 3 - setembro/dezembro 2014 - p. 773-792 
André Luiz Maranhão de Souza Leão, Thiago Ianatoni Camargo \& Rodrigo César Tavares Cavalcanti

Sensual só se relaciona com Jovial. Tal relação remete à erotização como um traço deste espírito jovem da marca. Podemos ver isso no seguinte trecho: “Começando pelo nome: Chilli Beans, pimenta vermelha quente. É um nome sensual, [...] um pouco erótico pra ser uma marca de óculos, mas tem a ver com uma imagem”.

Jovial também se relaciona com Distinta. Esta relação remete à associação da jovialidade da marca Chilli Beans como característica de sua distinção em relação às suas concorrentes, bem como à diferença entre seus consumidores e os de outras marcas. A seguinte passagem é elucidativa dista relação: “Eu acho que eles fazem exatamente pra comunicar que pessoa não deve comprar aqueles óculos. Eles conseguem comunicar isso muito bem e me dizer: 'Esses óculos não são pra você!’”.

Com Atenciosa, a relação de Jovial nos remete à noção de que a jovialidade da marca é constituída por conhecimento e intimidade na maneira com que os seus funcionários se relacionam com seus clientes. Isso se evidencia no seguinte trecho de entrevista: “Até a própria loja é composta de jovens, [...] ela é uma marca pra jovens, a loja tem pessoas jovens, descoladas, que estão ali pra facilitar, pra mostrar o que é bom, não tem muito empecilho pra nada”.

Finalmente, na relação de Jovial com Midiática, percebemos que a imagem de jovialidade da marca se solidifica pela forma como essa se apresenta na mídia, por meio de ações promocionais, como vemos no seguinte trecho: “Chilli Beans é uma marca bem jovial. [...] Atualmente, eu a tenho visto no Big Brother”.

A partir dessas três categorias já apresentadas (estilosa, autêntica e jovial), a maior parte das relações já foram apresentadas. Depois delas, aquela com mais relações é Atenciosa, que se relaciona com seis categorias, incluindo Estilosa, Autêntica e Jovial (relações já demonstradas). A estratégia da marca de lançar modelos diversificados semanalmente é vista como um cuidado da marca com seus consumidores, uma vez que os provê diferenciação, o que revela a relação de Atenciosa com Diversificada e com Distinta, como se evidencia no seguinte trecho: “... ela tem essa preocupação com o cliente. [...] Tanto é que a cada semana são produzidos modelos de óculos diferentes. A cada semana, eles tão com um novo leque de opções para os clientes”.

Já na relação com Mercantil, Atenciosa se refere ao entendimento de que o atendimento prestado tem a finalidade de alavancar lucratividade, como pode ser notado na passagem que se segue: “Antes tinha uma manutenção (dos óculos) e essa manutenção era gratuita. No entanto, hoje essa manutenção não é mais gratuita; é cobrada uma taxa”.

REAd | Porto Alegre - Edição 79 - N 3 - setembro/dezembro 2014 - p. 773-792 
Pimenta nos olhos dos outros é... Chilli Beans! A personalidade da marca aos “olhos” dos consumidores

Com cinco relações, Diversificada já foi apresentada em suas ligações com Estilosa, Autêntica e Atenciosa. Suas demais relações são com Acessível e Comum, em inter-relação que demonstra que a política de preços acessíveis e variedade de modelos são complementares e atrai uma ampla gama de consumidores, como se evidencia na seguinte passagem: “O patamar de preço é mais em conta, porque até, pelo que eu entendi, o conceito é você poder ter vários (modelos)”.

Comum também se relaciona a quatro categorias: Estilosa, Autêntica, Acessível e Diversificada. Acessível, conta com quatro relações: Diversificada, Estilosa, Autêntica e Comum. Distinta e Alegre, também com quatro relações cada, compartilham conexões com Autêntica, Jovial e Estilosa. Distinta relaciona-se ainda com Atenciosa, e Alegre com Divertida. Com três relações cada uma, aparecem Divertida e Midiática. As duas se relacionam com Estilosa e Jovial. Midiática se encontra ainda com Autêntica, e Diversificada com Alegre. Mercantil se relaciona com duas categorias: Estilosa e Atenciosa. Finalmente, Sensual é relacionada apenas a Jovial. Todas estas relações foram descritas anteriormente.

Em uma terceira etapa da análise, encontramos, nas relações observadas, unidades mais amplas de significado. Para isso, mapeamos, para além das relações nelas mesmas, grupos de categorias inter-relacionadas. Assim, chegamos à constatação de três perfis, conforme representado na Figura 1, aos quais demos os nomes de Exibicionista, Sociável e Comunicativa.

Duas categorias estavam presentes em mais de um perfil. Estilosa, que tem o maior número de relações, participa de todos os três perfis. Já Autêntica participa de dois do total de três perfis, sendo excluída apenas de Exibicionista. Desta forma, tais categorias, antes de contribuírem para a definição dos perfis identificados, sugerem aproximação entre aqueles que as compartilham, sendo as categorias exclusivas de cada grupo aquelas que mais contribuem para suas definições.

\section{CONSIDERAÇÕES FINAIS}

A presente pesquisa a analisar a Chilli Beans, por meio da identificação e avaliação das características humanas que compõem sua personalidade sob a ótica de seus consumidores. Conhecemos uma marca sociável, comunicativo e exibicionista.

O perfil definido como Exibicionista é composto por Jovial, Estilosa, Alegre, Divertida e Sensual. As quatro primeiras se relacionam entre si. Sensual é incorporada ao conjunto por meio de sua conexão com Jovial. As facetas destas categorias, quando

REAd | Porto Alegre - Edição 79 - N 3 - setembro/dezembro 2014 - p. 773-792 
André Luiz Maranhão de Souza Leão, Thiago Ianatoni Camargo \& Rodrigo César Tavares Cavalcanti

relacionadas, remetem-nos a uma aura jovial e de divertimento, que evoca a erotização, a provocação, e o apelo ao visual - ora estético, ora atmosférico - da marca.

O perfil Sociável é constituído pelas relações entre Autentica, Estilosa, Diversificada, Comum e Acessível. Neste caso, as cinco categorias conectam-se todas entre si. O sentido dos relacionamentos nos orientam a crer que os esforços emanam uma singularidade da marca, sejam estéticos, sejam de comportamento e destinam-se a diferentes identidades. As relações que apontam para a quantidade e a diversidade de elementos da marca, tanto no quantitativo de produtos, como número de alternativas de design, trazem à tona uma investida no sentido de atrair e agradar diversos públicos.

Finalmente, o perfil Comunicativa é o que carrega mais categorias: Estilosa, Atenciosa, Autêntica, Distinta, Jovial, Mercantil e Midiática. As cinco primeiras se conectam umas com as outras. Mercantil se encontra apenas com Atenciosa e Estilosa; por sua vez, Midiática liga-se apenas com autêntica e jovial. As relações edificadas entre essas categorias, como foi observado nos dados, remete à interatividade da marca. Mesmo que categorias como Atenciosa, Mercantil e Midiática emanem significados funcionais, suas conexões com as demais apontam para uma procura não apenas por comunicar sobre a marca, mas sim, localizá-la como assunto, que centralize os consumidores em torno do seu ethos.

Contudo, quando analisamos a interação entre as categorias de cada perfil, algumas particularidades podem ser consideradas. O exibicionismo da marca, ainda que singular, arrisca-se no exagero de seu estilo. Com sua sociabilidade, ao pretender abraçar diferentes identidades, acaba por ariscar a perda de seus status. Sua comunicabilidade, por fim, em certo aspecto, envereda pelo arriscado caminho venal que não é condizente com seu estilo.

Buscamos aqui interpretar os resultados encontrados por meio de insights a respeito da construção de significados das marcas, por meio da de compreensão da personalidade de marca. Com isto, vislumbramos contribuições tanto para a academia quanto para a prática de marketing. Por meio da marca escolhida, percebemos como, no processo relacional, os significados distintos que estabelecem a personalidade da marca emergem a partir de diferentes formas de manifestação da marca sob a ótica dos consumidores e não apenas esforços de comunicação; os consumidores personificam a marca a partir de sua experiência relacional com ela e não somente como resposta aos seus estímulos. Para a academia, este aspecto corrobora a distinção entre identidade e imagem de marca, acrescentando àquela uma dimensão relacional que normalmente não é considerada, uma vez tratar-se de um construto perceptual. Para os gestores e profissionais de marketing, os resultados sugerem que 
Pimenta nos olhos dos outros é... Chilli Beans! A personalidade da marca aos “olhos” dos consumidores

comunicações não massivas, tais como as de ponto de venda e redes sociais podem ter um significativo papel na imagem das marcas junto aos seus consumidores.

Devemos considerar aqui que esta pesquisa limitou-se a conhecer à marca Chilli Beans por meio dos consumidores de apenas uma região metropolitana do país (Recife). Por outro lado, o fato da cidade em questão ser litorânea e ter clima quente a maior parte do ano, pode contribuir para a percepção dos consumidores acerca de uma marca cuja imagem está fortemente alinhada com óculos de sol. Todavia, trata-se de um estudo exploratório, que teve o intuito de lançar luz sobre uma nova possibilidade de pesquisa. Assim, vislumbramos que pesquisas sobre outras marcas a partir desta abordagem hão de proporcionar uma consolidação acerca do conhecimento sobre a construção de significados para as marcas e sua relação com os consumidores.

\section{REFERÊNCIAS}

AAKER, D. A., Criando e administrando marcas de sucesso. São Paulo: Futura, 1996.

AAKER, J. L. Dimensions of brand personality. Journal of Marketing Research, v.34, n.3, p.347-356, 1997.

AÑAÑA, E. S.; NIQUE, W. M. O valor dos valores: avaliação de uma marca global por meio dos diversos brasis culturais. Revista de Administração Mackenzie, v. 10, n. 3, p. 153-181, 2009.

ANTUNES, J.; RITA, P. O marketing relacional como novo paradigma: uma análise conceptual. Revista Portuguesa e Brasileira de Gestão, v.7, n.2, p.36-46, 2008.

AZOULAY, A.; KAPFERER. J-N. (2003). Do brand personality scales really measure brand personality? Journal of Brand Management, v.11, n.2, p.143-155, 2003.

BAUER, M.; AARTS, B. A construção do corpus: um princípio para a coleta de dados qualitativos. In M. BAUER.; G. GASKEL (Eds) Pesquisa qualitativa com texto, imagem e som: um manual prático. Petrópolis: Vozes, 2002.

BAUER, M.; GASKELL, G.; ALLUM, N. C. Qualidade, quantidade e interesses do conhecimento - evitando confusões. In M. BAUER.; G. GASKEL (Eds) Pesquisa qualitativa com texto, imagem e som: um manual prático. Petrópolis: Vozes, 2002. 
André Luiz Maranhão de Souza Leão, Thiago Ianatoni Camargo \& Rodrigo César Tavares Cavalcanti

BERGER, P. L.; LUCKMANN, T. A construção social da realidade. 31ª ed. Petrópolis: Vozes, 2009.

BERNARD, H. R. Research methods in anthropology: qualitative and quantitative approaches. $2^{\mathrm{a}}$ ed. London: Sage, 1994.

BICHUETI, R. S.; BATTISTELA, L. F.; GROHMANN, M. Z. Personalidade de marca: Um estudo da percepção dos consumidores da Eny Comércio de Calçados. In: XIII SEMEAD. Anais... São Paulo: 2010.

BLACKSTON, M. Beyond brand personality: Building brand relationships. In: AAKER, D. A.; BIEL, A. Brand equity and advertising. Hillsdale, NJ: Lawrence Erlbaum Associates, 1993, p.113-34.

BRITO, C. Uma abordagem relacional ao valor da marca. Revista Portuguesa e Brasileira de Gestão, v.9, n.1-2, p.49-63, 2010.

CHILLI BEANS. Sítio eletrônico da marca. Disponível em: http://www.chillibeans.com.br/. Acesso em: 21/07/2014.

CRESCITELLI, E.; GIRALDI, J. M. E. Países como marcas: dificuldades no desenvolvimento de marca-país. Facef Pesquisa. v.12, n.03, p.269-285, 2009.

CRESWELL, J. Projeto de pesquisa: métodos qualitativos, quantitativos e mistos. Alegre: Artmed, 2010.

DALFOVO, M. S.; PEDROSO, A. A percepção dos clientes multimarcas referente ao novo posicionamento da marca Hering. Revista Interdisciplinar Científica Aplicada, v.2, n.2, p.0122, 2008.

DENZIN, N. K.; LINCOLN, Y. S. Paradigmatic controversies, contradictions, and emerging confluences. In: DENZIN, N. K.; LINCOLN, Y. S. (Eds.). The Sage Handbook of qualitative research. Sage Publications: Thousand Oaks, 2005.

ESCALAS, J. E.; BETTMAN, J. R. You are what they eat: the influence of reference groups in consumer's connections to brands. Journal of Consumer Psychology, v.13, n.3, p.339-348, 2003.

FINESTRALI, M.; GARRIDO, I. L. Uso de referências da identidade cultural brasileira no marketing internacional de produtos e marcas de luxo. Revista de Administração FACES Journal, v. 9, n. 3, p. 57-76, 2010. 
Pimenta nos olhos dos outros é... Chilli Beans! A personalidade da marca aos “olhos” dos consumidores

FISCHER, J. K. Comunicação integrada de marketing como estratégia de construção da personalidade de marca: A análise qualitativa de uma empresa têxtil. In: XXXIII Encontro da ANPAD. Anais... São Paulo: 2009.

FLICK, U. Introdução à pesquisa qualitativa. 3ª ed. Porto Alegre: Bookman/Artmed, 2009.

FOURNIER, S. (1998), Consumers and their brands: Developing relationship theory in consumer research. Journal of Consumer Research, v. 24, n.4, p.343-353, 1998.

GILL, R. Análise de discurso. In: BAUER, M.; GASKEL, G. (Eds), Pesquisa qualitativa com texto, imagem e som: um manual prático. Petrópolis: Vozes, 2002.

GROHMANN, B. Gender dimensions of brand personality. Journal of Marketing Research, v.46, n.1, p.105-19, 2009.

KELLE, U. Análise com auxílio de computador: codificação e indexação. In: BAUER, M.; GASKEL, G. (Eds), Pesquisa qualitativa com texto, imagem e som: um manual prático. Petrópolis: Vozes, 2002.

KELLER, K. L. How to navigate the future of brand management. Marketing Management, v.20, n.2, p.36-46, 2011.

KIM, J.; BAEK, T. H.; MARTIN, H. J. Dimensions of news media brand personality. Journalism \& Mass Communication Quarterly, v.87, n.1, p,117-34, 2010.

LEÃO, A. L. M. S.; SOUZA NETO, A. F.; MELLO, S. C. B. Compreendendo os valores das marcas: aplicação da lista de valores em diferentes indústrias. Revista de administração Contemporânea, v.11, n.2, p. 27-48, 2007.

; MELLO, S. B. C.; VIEIRA, R. S. G. O papel da teoria no método de pesquisa em Administração. Revista Organizações em Contexto, v.5, n.10, p.1-16, 2009.

LEITE, R. de C.; WINCK, C. A.; ZONIN, V. J. A Influência do estrangeirismo no processo de construção da marca no agronegócio. Brazilian Business Review, v.9, n.1, p.110-133, 2012.

MADRIGAL R.; BOUSH, D. M. Social responsibility as a unique dimension of brand personality and consumers' willingness to reward. Psychology \& Marketing, v.25, n.6, p.53864, 2008. 
André Luiz Maranhão de Souza Leão, Thiago Ianatoni Camargo \& Rodrigo César Tavares Cavalcanti

MALÄR, L.; KROHMER, H.; HOYER, W. D.; NYFFENEGGER, B. Emotional brand attachment and brand personality: The relative importance of the actual and the ideal self. Journal of Marketing, v.75, n.4, p.35-52, 2011.

MATTOS, P. L. C. L. A entrevista não estruturada como forma de conversação: razões e sugestões para sua análise. Revista de Administração Pública, v.39, n.4, p.823-47, 2005.

McCRACKEN, G. Who is the celebrity endorser? Cultural foundations of the endorsement process. Journal of Consumer Research, v.16, n.3, p.310-21, 1989.

;. Culture and consumption: A theoretical account of the structure and movement of the cultural meaning of consumer goods. Journal of Consumer Research, v.13, n1, p.71-84, 1986.

MENGARELLI, A. P. C. Dimensões da personalidade de marca: Construção e validação de uma escala adaptada aos consumidores adolescentes. In: XXXII Encontro da ANPAD.

Anais... Rio de Janeiro: 2008.

MERRIAN, S. Qualitative research and case study applications in education. San Francisco: Jossey-Bass, 1998.

MILES, M. B.; HUBERMAN, A. M. Qualitative data analysis: an expanded source book. London: Sage Publications, 1994.

OLIVEIRA, M. E. R.; GALLI, L. C. L. A.; CÔNSOLI, M. A.; CASTRO, L. T. e. Gestão de marcas emocionais: um estudo exploratório no setor automotivo de veículos leves. REMark, v.9, n.1, p.91-110, 2010.

PAIVA JR., F. G.; LEÃO, A. L. M. S.; MELLO, S. C. B. Validade e confiabilidade na pesquisa qualitativa em Administração. Revista de Ciências da Administração, v.13, n.31, p.190-209, 2011.

PALMATIER, R. W.; JARVIS, C. B.; BECHKOFF, J. R.; KARDES, F. R. The role of customer gratitude in relationship marketing. Journal of Marketing, v.73, n.5, p.1-18, 2011.

PARK, J.; ROEDDER JOHN, D. Got to get you into my life: Do brand personalities rub off on consumers? Journal of Consumer Research, v.37, n.4, p.655-69, 2010.

PATSIOURA, F.; MALAMA, E-I. ; VLACHOPOULOU, M. A relationship marketing model for brand advertising websites: An analysis of consumers' perceptions. International Journal of Management, v.28, n.4, p.72-91, 2011.

REAd | Porto Alegre - Edição 79 - N 3 - setembro/dezembro 2014 - p. 773-792 
Pimenta nos olhos dos outros é... Chilli Beans! A personalidade da marca aos “olhos” dos consumidores

PETROSKI, T. A. B.; BAPTISTA, P. P.; MARCHETTI, R. Z. Cidades como marcas: Análise da aplicabilidade do conceito de personalidade de marcas ao contexto de cidades. In: XXXIV Encontro da ANPAD. Anais... Rio de Janeiro: 2010.

PONTES, N. G.; PARENTE, J. G. Personalidade de marca: Como se mede? In: XXXII Encontro da ANPAD. Anais... Rio de Janeiro: 2008.

ROKEACH, M. Beliefs, attitudes and values: a theory of organization and change. Hoboken: Jossey-Bass, 1968

;. The nature of human values. New York: The Free Press, 1973.

SERRALVO, F. A.; FURRIER, M. T. reposicionamento de marcas: estudo de casos brasileiros. Revista brasileira de gestão e negócios. v.10, n.26, p. 1-16, 2008.

SONNIER, G.; AINSLE, A. Estimating the value of brand-image associations: The role of general and specific brand image. Journal of Marketing Research, v.48, n.3, p.518-31, 2011.

STILLER, G. F. Analyzing everyday texts: discourse, rhetoric, and social perspectives. Thousand Oaks: Sage Publications, 1998.

SUNG, Y.; CHOI, S. M. “I won't leave you although you disappoint me”: The interplay between satisfaction, investment, and alternatives in determining consumer-brand relationship commitment. Psychology \& Marketing, v.27, n.11, p.1050-1073, 2010.

SWAMINATHAN, V.; PAGE, K. L.; GÜRHAN-CANLI, Z. “My” brand or “our” brand: The effects of brand relationship dimensions and self-construal on brand evaluations. Journal of Consumer Research, v.34, n.2, p.248-259, 2007.

; STILLEY, K. M.; AHLUWALIA, R. When brand personality matters: The moderating role of attachment styles. Journal of Consumer Research, v.35, n.6, p.985-1002, 2009.

THIRY-CHERQUES, H. R. Saturação em pesquisa qualitativa: estimativa empírica de dimensionamento. Revista PMKT. n.3, p.20-27, 2009.

WITTGENSTEIN, L. Investigações filosóficas. Petrópolis: Vozes, 2005. 